\title{
Dossiê
}

\section{A literatura infantil na educação em direitos humanos: fundamentos e ideologia}





\title{
Direitos humanos e literatura: porque os livros mudam as pessoas e as pessoas mudam o mundo ${ }^{1}$
}

- Derechos humanos y literatura: por qué los libros cambian a las personas y las personas cambian el mundo

- Human rights and literature: why books change people and people change the world

\author{
Andréia Inês Hanel Cerezoli² \\ Francisca Monteiro da Silva Perez ${ }^{3}$ \\ José Antonio Ribeiro de Moura ${ }^{4}$ \\ Orleane Oliveira Jambeiro ${ }^{5}$
}

Resumo: Este artigo trata da educação em Direitos Humanos entendida como uma pedagogia comprometida com a promoção da dignidade de todo e qualquer ser humano. O objetivo da pesquisa é demonstrar, por meio de atividades, como a literatura infantil pode constituir material inestimável para

1 Este artigo é um trabalho cooperativo desenvolvido junto ao GPLTPP - Grupo de pesquisa em linguagem, tecnologias e políticas públicas da UERGS - RS liderado pela professora Dr. Ana Carolina Martins e formado por professores de diferentes instituições de ensino do Brasil.

2 Doutora em Letras, Professora de Língua Portuguesa e Linguística da Universidade Federal da Fronteira Sul (UFFS). andreia.cerezoli@uffs.edu.br

3 Mestre em Educação pela UFRN, psicopedagoga do Núcleo de Educação a Distância da Universidade Federal Rural do Semi-Árido (NEaD/UFERSA). francisca.perez@ufersa.edu.br

4 Mestre em Administração pela Universidade Metodista de São Paulo, Docente Ensino Superior na Universidade Feevale/RS. mourareis@uol.com.br

5 Graduada em Letras, Especialista em Gestão de Organizações Educacionais pela Universidade do Estado da Bahia (UNEB). É professora da educação básica. jambeiroorleane@gmail.com 
a educação em Direitos Humanos. A metodologia empreendida na pesquisa tem caráter bibliográfico. A revisão bibliográfica, em nenhum momento, visa esgotar algum tópico apresentado, mas construir um cenário capaz de ilustrar os pressupostos teóricos que alicerçam as sugestões apresentadas e discutidas. Os resultados demonstram a importância da definição dos conceitos teóricos que orientam as discussões, visto as limitações, deturpações e inovações que os conceitos aqui abordados concentram. Concluímos que a contação de histórias, com o cuidado de não tornar a leitura mecânica, é uma atividade em que o contador e o ouvinte têm um encontro no espaço da fantasia, o que pode, efetivamente, modificar as pessoas. Já a metodologia adotada para a escrita deste artigo consiste em apresentar os conceitos teóricos como um passeio pela literatura, afinal Gabriel García Márquez, que dispensa qualificações afirma $A$ vida não é o que a gente viveu e sim o que a gente recorda e como recorda, para contá-la.

Palavras-chave: Direitos humanos. Literatura. Contação de histórias.

Resumen: Este artículo trata sobre la educación en derechos humanos entendida como una pedagogía comprometida con la promoción de la dignidad de todos y cada uno de los seres humanos. El objetivo de la investigación es demostrar, a través de actividades, cómo la literatura infantil puede ser un material invaluable para la educación en derechos humanos. La metodología utilizada en la investigación tiene carácter bibliográfico. La revisión bibliográfica, en ningún momento, pretende agotar cualquier tema presentado, sino construir un escenario capaz de ilustrar los supuestos teóricos que sustentan las sugerencias presentadas y discutidas. Los resultados demuestran la importancia de definir los conceptos teóricos que guían las discusiones, dadas las limitaciones, tergiversaciones e innovaciones en las que se concentran los conceptos aquí discutidos. Concluimos que contar historias, cuidando que la lectura no sea mecánica, es una actividad en la que el narrador y el oyente tienen un encuentro en el espacio de la fantasía, que efectivamente puede cambiar a las personas. La metodología adoptada para la redacción de este artículo consiste en presentar los conceptos teóricos como un paseo por la literatura, al fin y al cabo Gabriel García Márquez, que no necesita titulación, afirma "La vida no es lo que vivimos, sino lo que recordamos, y cómo se recuerda. para contarlo.

Palabras clave: Derechos humanos. Literatura. Cuentacuentos. 


\begin{abstract}
This article deals with human rights education understood as a pedagogy committed to promoting the dignity of each and every human being. The objective of the research is to demonstrate, through activities, how children's literature can be invaluable material for human rights education. The methodology used in the research has a bibliographic character. The bibliographic review, at no time, aims to exhaust any topic presented, but to build a scenario capable of illustrating the theoretical assumptions that underpin the suggestions presented and discussed. The results demonstrate the importance of defining the theoretical concepts that guide the discussions, given the limitations, misrepresentations and innovations that the concepts discussed here concentrate on. We conclude that storytelling, taking care not to make reading mechanical, is an activity in which the storyteller and the listener have an encounter in the space of fantasy, which can effectively change people. The methodology adopted for the writing of this article consists of presenting the theoretical concepts as a walk through literature, after all Gabriel García Márquez, who needs no qualifications, affirms "Life is not what we lived, but what we remember, and how it remembers to tell it.
\end{abstract}

Keywords: Human rights. Literature. Storytelling.

\title{
Introdução
}

Mario Quintana, inigualável poeta da literatura brasileira, reconhece que todo o potencial da literatura está na(s) leitura(s) das pessoas e na maneira como são desafiadas pelo livro. Para o poeta "Livros não mudam o mundo, quem muda o mundo são as pessoas. Os livros só mudam as pessoas" ${ }^{\prime \prime}$, por isso o título desta pesquisa faz uma homenagem ao poeta brasileiro.

Em relação à pesquisa, três pontos devem ser esclarecidos: (1) metodologicamente: (a) é desenvolvida por docentes da educação básica e do ensino superior; (b) agrega experiência docente em ensino presencial e EaD; e (c) une as esferas municipais, estaduais e federais de educação; (2) cientificamente: brota como um grito de resistência das ciências humanas e sociais que, em 2020, foram taxadas como áreas não essenciais e, por isso, excluídas pelo $\mathrm{CNPq}^{7}$ da chamada pública para concessão de 25 mil bolsas do programa iniciação científica; e (3) tematicamente: aproxima duas áreas de pesquisa, a literatura infantil e os direitos humanos, cuja práxis, normalmente, é discutida por grupos muito distintos.

6 Fonte: https://listafrases.com/frase/11618.

7 Conselho Nacional de Desenvolvimento Científico e Tecnológico. 
Nesse contexto, o objetivo da pesquisa é demonstrar, por meio de atividades, como a literatura infantil pode constituir material inestimável para a Educação em Direitos Humanos. Isso porque, partimos do pressuposto que a literatura é um material de riquíssimo potencial para o trabalho de Educação em Direitos Humanos. Nossa contribuição consiste em indicar atividades e justificá-las a partir dos princípios da Educação em Direitos Humanos, dados não encontrados nas referências consultadas.

Pela tradicional distância dos temas: literatura e Educação em Direitos Humanos, organizamos o trabalho em duas seções: (1) Direitos humanos: claro enigma, em que situamos aos leitores os conceitos teóricos: (a) Direitos Humanos; (b) Políticas Públicas; e (c) Educação em Direitos Humanos, que orientam a proposição e a análise das atividades sugeridas; e (2) Literatura e Direitos Humanos: o resto é silêncio, em que situamos o conceito de literatura que norteia nossa investigação e o corpus: o conto Os três porquinhos.

\title{
1 Direitos humanos: Claro enigma
}

\author{
A criança que pensa em fadas e acredita nas fadas \\ Age como um deus doente, mas como um deus. \\ Porque embora afirme que existe o que não existe \\ Sabe como é que as cousas existem, que é existindo, \\ Sabe que existir existe e não se explica, \\ Sabe que não há razão nenhuma para nada existir, \\ Sabe que ser é estar em algum ponto \\ Só não sabe que o pensamento não é um ponto qualquer.
}

A criança que pensa em fadas

Em 1951, o poeta Carlos Drummond de Andrade, publica a obra Claro enigma, à qual fazemos alusão nesta pesquisa, pela sua construção semântica. Semanticamente, enigma refere algo de difícil resolução, enquanto claro está em perfeita oposição semântica, referindo algo transparente, compreensível. A genialidade de Drummond em perceber que algumas temáticas são tão evidentes que tornam difícil a definição e a compreensão pode, atualmente, justificar as polêmicas em relação ao sentido e ao reconhecimento social dos Direitos Humanos. Nesse sentido é fácil citar a expressão "direitos humanos" evidenciando sua repercussão social, mas difícil é definir, quer semanticamente, quer socialmente, o alcance e os limites dessa expressão, daí seu caráter enigmático.

Benevides (1998), grande pesquisadora do tema direitos humanos reconhece as limitações e a deturpação voluntária que envolve a temática. A pesquisadora afirma: 
Provavelmente vocês já ouviram muitas vezes referência aos direitos humanos no sentido pejorativo ou excludente, no sentido de identificá-los com direitos dos bandidos. Quantas vezes vocês já ouviram - principalmente depois do noticiário sobre crimes de extrema violência: Ah! E os defensores dos direitos humanos, onde é que estão? Então, a nossa primeira tarefa é deixar claro do que nós estamos falando tanto quando nos referimos a direitos dos cidadãos, como quando nos referimos a direitos humanos, com a premissa de que associamos direitos humanos à idéia central de democracia e às idéias básicas envolvidas no tema mais amplo da educação. (BENEVIDES, 1998, p. 39)

Nesse cenário, esta seção tem como objetivo delimitar o conceito epistemológico de direitos humanos assumido nesta pesquisa. A definição de direitos humanos que assumimos aqui é proposta por Benevides $(2008$, p. 3):

Direitos humanos são aqueles comuns a todos sem distinção alguma de etnia, nacionalidade, sexo, classe social, nível de instrução, religião, opinião política, orientação sexual ou de qualquer tipo de julgamento moral. São aqueles que decorrem do reconhecimento da dignidade intrínseca de todo ser humano.

Benevides (1998) caracteriza os direitos humanos como: (1) universais; (2) naturais; (3) históricos; (4) indivisíveis; e (5) irreversíveis. O Quadro I - Características dos Direitos Humanos - elenca as características propostas por Benevides e suas definições.

Quadro I - Características dos Direitos Humanos

\begin{tabular}{|l|l|l|l|l|}
\hline \multicolumn{7}{|c|}{ DIREITOS HUMANOS } \\
\hline UNIVERSAIS & NATURAIS & HISTÓRICOS & INDIVISÍVEIS & IRREVERSÍVEIS \\
\hline $\begin{array}{l}\text { Ultrapassam os } \\
\text { limites físicos e } \\
\text { políticos das nações. }\end{array}$ & $\begin{array}{l}\text { Existem antes de } \\
\text { qualquer lei. Não } \\
\text { precisam estar espe- } \\
\text { cificados em uma lei, } \\
\text { para serem exigidos, } \\
\text { reconhecidos, prote- } \\
\text { gidos e promovidos. }\end{array}$ & $\begin{array}{l}\text { Acréscimo e aper- } \\
\text { feiçoamento de } \\
\text { condições conquis- } \\
\text { tadas ao longo do } \\
\text { tempo. }\end{array}$ & $\begin{array}{l}\text { Impossibilidade de } \\
\text { separação entre o } \\
\text { respeito às liber- } \\
\text { dades individuais e a } \\
\text { garantia dos direitos } \\
\text { sociais. }\end{array}$ & $\begin{array}{l}\text { À medida que } \\
\text { são proclamados, } \\
\text { tornando-se direitos } \\
\text { positivos fundamen- } \\
\text { tais, não podem ser } \\
\text { revogados. }\end{array}$ \\
\hline
\end{tabular}

Fonte: Elaborado pelos autores com base em Benevides $(1998,2000)^{8}$.

Já para Antonio Candido (2011, p. 174) "[...] pensar em direitos humanos tem um pressuposto: reconhecer que aquilo que consideramos indispensável

8 Palestra de abertura do Seminário de Educação em Direitos Humanos, São Paulo, 18/02/2000. A autora agradece a importante contribuição do Prof. Fábio Konder Comparato. 
para nós é também indispensável para o próximo.". Aí, qualquer um de nós listaria uma série de itens indispensáveis: comida, casa, trabalho, segurança etc.

Essa imersão, longe de ser unanimidade, nos autoriza a problematizar movimentos voltados para assegurar: (1) a compreensão da dimensão conceitual do termo "direitos humanos"; (2) a efetivação das condições de dignidade a todo e qualquer ser humano; e (3) a promoção da educação em direitos humanos.

Os pontos problematizados nos levam a percorrer duas possibilidades: (a) as políticas públicas; e (b) a educação. Reconhecemos que os dois caminhos apresentados serão separados apenas para fins didáticos de definição, mas é comum a atuação das duas frentes em uma mesma proposta voltada para a garantia da dignidade do ser humano.

\subsection{Políticas públicas: Os tambores silenciosos}

Nesta seção, recorremos ao romance de Josué Guimarães, Os tambores silenciosos (1997), para problematizar o tema das políticas públicas. Josué Guimarães, com humor, denuncia em Os tambores silenciosos ações de cerceamento da liberdade promovidas pelo prefeito em nome da "felicidade do povo", pois como indica Calvino (1993, p. 29) "Sabemos que se pode muito bem dar aparência de estilo e dignidade às piores ações [...]". Nessa perspectiva, ressaltamos a orientação ideológica dos governos na elaboração, execução e avaliação das políticas públicas. Assim, o objetivo desta seção é comparar algumas definições de políticas públicas.

Souza (2006) elenca algumas definições de políticas públicas, pois de acordo com a autora não há consenso na área. O Quadro II - Definições de Políticas Públicas - permite a comparação entre definições.

Quadro II - Definições de Políticas Públicas

\begin{tabular}{|c|c|c|c|c|}
\hline \multicolumn{5}{|c|}{ POLÍTICAS PÚBLICAS } \\
\hline Mead & Lynn & Peters & Laswell & Dye \\
\hline $\begin{array}{l}\text { Um campo dentro } \\
\text { do estudo da } \\
\text { política que analisa } \\
\text { o governo à luz de } \\
\text { grandes questões } \\
\text { públicas. }\end{array}$ & $\begin{array}{l}\text { Conjunto de ações } \\
\text { do governo que } \\
\text { irão produzir efeitos } \\
\text { específicos. }\end{array}$ & $\begin{array}{l}\text { Soma das atividades } \\
\text { dos governos, que } \\
\text { agem diretamente } \\
\text { ou através de } \\
\text { delegação, e que } \\
\text { influenciam a vida } \\
\text { dos cidadãos. }\end{array}$ & $\begin{array}{l}\text { Decisões e análises } \\
\text { sobre política pública } \\
\text { implicam responder } \\
\text { às seguintes } \\
\text { questões: quem } \\
\text { ganha o quê, por quê } \\
\text { e que diferença faz. }\end{array}$ & $\begin{array}{l}\text { O que o governo } \\
\text { escolhe fazer ou não } \\
\text { fazer. }\end{array}$ \\
\hline
\end{tabular}

A autora destaca que a definição de Laswell é a mais difundida, indicando uma visão menos ingênua de que as políticas públicas têm como 
condição sine qua non influenciar a vida dos cidadãos de modo geral. Ainda em relação ao Quadro II, nos parece importante destacar a definição de Dye (1984) ao explicitar que a opção de um governo em não elaborar, executar ou avaliar uma determinada ação também configura uma política pública, pois "A formulação de políticas públicas constitui-se no estágio em que os governos democráticos traduzem seus propósitos e plataformas eleitorais em programas e ações que produzirão resultados ou mudanças no mundo real." (SOUZA, 2006, p. 26). Logo, a não formulação de políticas públicas voltadas para a garantia da dignidade de todo e qualquer ser humano revela os propósitos daquele determinado governo.

A pesquisadora ainda destaca que do ponto de vista teórico-conceitual, a política pública em geral e a política social em particular são campos multidisciplinares, cujo enfoque está nas explicações sobre a natureza da política pública e seus processos. "As políticas públicas repercutem na economia e nas sociedades, daí por que qualquer teoria da política pública precisa também explicar as inter-relações entre Estado, política, economia e sociedade." (SOUZA, 2006, p. 25).

Como nosso propósito não é esgotar o tema, mas problematizar uma das vias possíveis para a implementação e efetivação da garantia dos direitos humanos a todo e qualquer cidadão, as políticas públicas, cuja elaboração compete aos governos, na próxima seção problematizamos uma segunda via, a educação, cuja competência fica a cargo dos educadores.

\subsection{Educação: a alavanca das mudanças sociais}

Esta seção, além de prestar uma homenagem a Paulo Freire, por acreditar no poder da educação como alavanca para mudar a realidade dos mais pobres e explorados, parte de dois pressupostos fundamentais: (1) a existência dos direitos humanos como reconhecimento da dignidade intrínseca de todo ser humano torna-se necessária à medida que há a constatação de que parte dos seres humanos não tem sua dignidade garantida; e (2) se alguns seres humanos não têm sua dignidade garantida é urgente a mudança social desse quadro.

Considerando-se pertinentes esses pressupostos, esta seção tem como objetivo caracterizar a educação em direitos humanos, já que a educação em geral, por si só, não é capaz de garantir a promoção da dignidade de todo e qualquer ser humano.

Benevides (2008) pontua radicalmente que a educação para todos é condição sine qua non para a cidadania. Constatação que reforça a ideia de Freire (1993, p. 12, grifos do autor) "[...] não há crianças se evadindo das escolas, como não há crianças fora das escolas como se não estivessem dentro só 
porque não quisessem, mas há crianças ora proibidas pelo sistema de entrar nas escolas, ora de nelas permanecer.."

A convergência dos autores quanto ao acesso e à permanência da criança na escola encaminha para a postura pedagógica do professor. Nas palavras de Benevides (2008) "Adotar o compromisso pedagógico com o desenvolvimento dessas virtudes significa trabalhar com a perspectiva de mudar mentes, o que é, sem dúvidas, tarefas das mais difíceis.".

O Quadro III - Trabalho do educador em Direitos Humanos - faz uma síntese das características que um educador em Direitos Humanos deve considerar ao adotar uma pedagogia comprometida com a promoção da dignidade de todo e qualquer ser humano.

Quadro III - Trabalho do educador em Direitos Humanos

\begin{tabular}{|c|}
\hline EDUCAÇÃO EM DIREITOS HUMANOS \\
\hline PONTOS ESSENCIAIS \\
\hline $\begin{array}{l}\text { - natureza permanente, continuada e global; } \\
\text { - complexa e difícil, mas não impossível; } \\
\text { - uma utopia que se realiza na própria tentativa de realizá-la; } \\
\text { - necessariamente voltada para a mudança; } \\
\text { inculcação de valores para atingir corações e mentes e não apenas instrução, } \\
\text { - meramente transmissora de conhecimentos; } \\
\text { - compartilhada por aqueles que estão envolvidos no processo educacio- } \\
\text { nal - educadores e educandos - ou ela não será educação e muito menos } \\
\text { em direitos humanos. }\end{array}$ \\
\hline OBJETIVOS \\
\hline $\begin{array}{l}\text { - essencialmente a formação de uma cultura de respeito à dignidade hu- } \\
\text { mana através da promoção e da vivência dos valores da liberdade, da } \\
\text { justiça, da igualdade, da solidariedade, da cooperação, da tolerância e } \\
\text { da paz; } \\
\text { - criar, influenciar, compartilhar e consolidar mentalidades, costumes, há- } \\
\text { bitos e comportamentos que decorrem, todos, daqueles valores essen- } \\
\text { ciais citados - os quais devem se transformar em práticas. }\end{array}$ \\
\hline
\end{tabular}




\section{ORIENTAÇÕES METODOLÓGICAS}

- INTERDISCIPLINARIDADE: não se pretende uma nova disciplina, mas uma formação abrangente;

- PARTICIPAÇÃO NO TRABALHO DA ESCOLA: compreensão da íntima relação entre direitos humanos e formas de participação no trabalho da escola: colaboração, respeito, pluralismo, responsabilidade, prestação de contas;

- COTIDIANO ESCOLAR: constatação da presença ou ausência, de defesa ou de violação de quaisquer direitos no cotidiano escolar;

- REFERENCIAL TEÓRICO: a realidade social, econômica, política, cultural do meio, como referencial teórico;

- DIREITOS FUNDAMENTAIS: a compreensão efetiva sobre a integralidade e a indivisibilidade dos direitos fundamentais, seu contexto histórico, seu caráter público e reclamável;

- APRENDIZAGEM: ligada à vivência do valor da igualdade em dignidade e direitos para todos; propiciar o desenvolvimento de sentimentos e atitudes de cooperação e solidariedade;

- AVALIAÇÃO: não contar com resultados imediatos.

CONCEPÇÃO DE SUJEITO

- TOLERANTE: a educação para a tolerância se impõe como um valor ativo vinculado à solidariedade e não apenas como tolerância passiva da mera aceitação do outro, com a qual pode-se não estar solidário;

- RESPONSÁVEL: perceber as consequências pessoais e sociais de cada escolha;

- PARTICIPANTE: crítico, responsável, comprometido com a mudança daquelas práticas e condições da sociedade que violam e negam os direitos humanos.

- AUTÔNOMO: intelectual e afetivamente, sujeito de direitos e de deveres, capazes de julgar, escolher, tomar decisões, serem responsáveis e prontos para exigir que não apenas seus direitos, mas, também, os direitos dos outros sejam respeitados e cumpridos.

Fonte: elaborado pelos autores com base em Benevides (1998, 2000, 2008). 
Assim caracterizado, o trabalho do educador em Direitos Humanos parece uma utopia, longe de ser alcançada antes de reformulações na formação inicial de professores, no sistema escolar etc. Mas Freire (1993, p.38) alerta "[...] o que não é correto, porém, é esperar que as transformações materiais se processem para que depois comecemos a encarar corretamente o problema da leitura e da escrita. A leitura crítica dos textos e do mundo tem que ver com a sua mudança em processo..". Considerando esse um argumento válido, sentimo-nos encorajados para apresentar a segunda seção desta pesquisa, que toma a literatura como material para a promoção da educação em Direitos Humanos.

\title{
2. Literatura e direitos humanos: $O$ resto é silêncio
}

\author{
Oh! que saudades que tenho \\ Da aurora da minha vida, \\ Da minha infância querida \\ Que os anos não trazem mais! \\ Que amor, que sonhos, que flores. \\ Naquelas tardes fagueiras \\ À sombra das bananeiras, \\ Debaixo dos laranjais! \\ Como são belos os dias \\ Do despontar da existência! [...] \\ Meus oito anos \\ Casimiro de Abreu
}

O romance O resto é silêncio de Erico Veríssimo (1941) foi escolhido como subtítulo desta seção por tocar em problemas sociais como o suicídio. Logo, reforça nosso argumento em prol da utilização da literatura como material acessível para a educação em Direitos Humanos que visa garantir a dignidade a todas as pessoas.

Nesta seção temos como objetivo mostrar como a literatura pode caracterizar um material precioso para a concretização da educação em direitos humanos. Antes de aprofundar essa discussão, pontuamos que assumimos aqui o conceito de literatura proposto por Candido (2011, p. 176)

\begin{abstract}
Chamarei de literatura, da maneira mais ampla possível, todas as criações de toque poético, ficcional ou dramático em todos os níveis de uma sociedade, em todos os tipos de cultura, desde o que chamamos de folclore, lenda, chiste, até as formas mais complexas e difíceis da produção escrita das grandes civilizações.
\end{abstract}

A partir de um conceito de literatura amplo, Candido entende a literatura como uma necessidade universal que precisa ser satisfeita e cuja sa- 
tisfação configura um direito de todos. As sociedades criam manifestações poéticas, ficcionais ou dramáticas de acordo com impulsos, crenças, sentidos, normas etc. a fim de reforçar a atuação desses em cada indivíduo. Por outro lado, a literatura "[...] não é uma experiência inofensiva, mas uma aventura que pode causar problemas psíquicos e morais, como acontece com a própria vida, da qual é imagem e transfiguração." (CANDIDO, 2011, p. 178). Eis o ponto de convergência entre a literatura e os direitos humanos - a humanização. Para Candido (2011, p. 182) a humanização é um processo que permite "[...] o exercício da reflexão, a aquisição do saber, a boa disposição com o próximo, o afinamento das emoções, a capacidade de penetrar nos problemas da vida, o senso da beleza, a percepção da complexidade do mundo e dos seres, o cultivo do humor.".

Porém, temos a consciência de que é preciso mais do que estimular a leitura da literatura é preciso questioná-la, compará-la, desvendá-la. Ações que nem sempre são fáceis, por isso o planejamento e a coragem do professor em promovê-las. Freire afirma $(1993$, p. 37) "[...] a leitura em grupo faz emergir diferentes pontos de vista que, expondo-se uns aos outros enriquecem a produção da inteligência do texto.".

Ainda em relação ao grupo, ao espaço escolar, Benevides afirma:

[...] no sistema de ensino, desde a escola primária até a universidade, a escola pública é um locus privilegiado pois, por sua própria natureza, tende a promover um espírito mais igualitário, na medida em que os alunos, normalmente separados por barreiras de origem social, aí convivem. Na escola pública o diferente tende a ser mais visível e a vivência da igualdade, da tolerância e da solidariedade impõe-se com maior vigor. $(2000$, p. 9)

A partir do conceito de literatura proposto por Candido aqui, assumido e do reconhecimento do potencial da literatura no processo de humanização dos sujeitos, ainda nos cabe justificar nosso corpus de análise: Os três porquinhos.

Os três porquinhos é caracterizado um clássico da literatura infantil e, por isso, na percepção de Calvino (1993, p. 11) “Um clássico é um livro que nunca terminou de dizer aquilo que tinha para dizer.".

Na sequência sugerimos uma série de atividades, elaboradas a partir do clássico Os três porquinhos que acreditamos contribuir para a educação em Direitos Humanos.

\subsection{Os três porquinhos: além do "viveram felizes para sempre"}

Inicialmente, reconhecemos que há várias versões de Os três porquinhos, mais ou menos modificadas pelas suas releituras e reescritas. No entanto, é possível verificar que a essência da narrativa é mantida em todas as versões. Trazemos, para fins de ilustração, uma das versões 
Três porquinhos irmãos foram morar numa floresta. E para se proteger dos lobos decidiram construir suas casas. O mais novinho só queria brincar, fez rapidinho uma casinha de palha e saiu a passear. O do meio gostava de tocar flauta. Então, fez uma casinha de madeira e saiu para tocar. $O$ mais velho, prevenido, gastou todo o seu tempo fazendo uma linda casa de tijolos. À noite o lobo resolveu atacar. E num só sopro, derrubou a casinha de palha. O porquinho correu para a casa de madeira do irmão, mas o lobo derrubou esta também. Os dois porquinhos foram à casa do irmão mais velho e ficaram quietinhos esperando. O lobo chegou e soprou, soprou, soprou, mas não conseguiu derrubar a casa. O lobo tentou entrar pela chaminé da lareira, mas os porquinhos prevenidos acenderam ali uma fogueira. Quando o lobo chegou perto, chamuscou o rabo no fogo e saiu correndo feito louco e nunca mais voltou. (CONTOS CLÁSSICOS, 2002, n. 7).

Uma segunda observação, agora de natureza didática, acreditamos também ser necessária. Não vamos indicar uma faixa etária ou escolar específica para as atividades, pois acreditamos que cada professor, a partir da vivência com seus alunos, saberá quais atividades poderá sugerir àquela determinada turma.

\section{Preparação para a história}

Inicialmente, sugerimos que o professor estimule a curiosidade dos alunos para a história. Sugestões:

CAIXA MÁGICA:

O professor coloca boneco dos três porquinhos em uma caixa fecha da e por uma abertura, os alunos devem tocar, sentir, apalpar para descobrir os personagens da história;

\section{JOGO DA MEMÓRIA:}

O professor prepara um jogo da memória com os personagens princi pais da história. Divide a turma em grupos e, após todos concluírem o jogo, que pode ser explorado mais de uma vez, pede que os alunos observem as figuras e adivinhem a história;

\section{LETRAS EMBARALHADAS:}

Cada dupla de alunos recebe as letras do título Os três porquinhos, embaralhadas, para montar o título, que ainda não sabem. Deverão utilizar todas as letras. -

\section{CASA, MORADOR, TEMPESTADE}

Trata-se de uma variação da brincadeira popular Coelhinho sai da toca. 
Em trios, os alunos deverão determinar dois alunos para representar a CASA, um o MORADOR. Um aluno, representando o MORADOR, fica rá sem CASA. O professor dará os comandos:

- CASA, então os alunos que representam a CASA deverão pro curar um novo MORADOR.

- MORADOR, os alunos que representam o MORADOR deverão procurar uma nova CASA.

- TEMPESTADE, todos deverão procurar novas formação.

Acreditamos que o professor tem condições de despertar a curiosidade dos alunos para a história de muitas maneiras. As sugestões indicadas cumprem apenas a função de ilustração da importância do momento de preparação para a história e na identificação daquilo que os alunos já sabem sobre história, que representações fazem da história.

\section{Contação da história}

Eis a grande atividade. Acreditamos que o professor deve preparar a contação da história. Na medida do possível deve mostrar o livro, trabalhar a sua voz, apreender a atenção do aluno. Para Sisto $(2012$, p. 11) "Contar histórias é o exercício de cidadania e a linguagem artística mais democrática que eu conheço: não exige um espaço fechado nem aparato e tecnologias específicos. Basta um que conte e um que ouça.." Por isso, a contação da história já configura a responsabilidade do professor com o trabalho da escola, não se trata apenas de abrir um livro e repeti-lo mecanicamente, mas do estudo e da preparação, do trabalho com a voz, com o corpo, com o silêncio.

\section{Atividades}

- Passear pelo bairro da escola e observar as casas do bairro

- Identificar o valor de diferentes tipos de materiais: tijolo, madeira etc.

- Relacionar o tipo de moradia com o tipo de clima: iglu, palafita etc.

- Pesquisar a relação do tipo de material da casa com a questão do iso

- lamento térmico: barro, madeira etc.

- Recortar diferentes tipos de casas.

Nessa atividade os alunos devem ser orientados para perceber as diferentes moradias. Suas cores, seus materiais, seus sistemas de segurança, seus tamanhos etc. Devem ser orientados para perceber se no seu contexto há pessoas com privação de moradia, moradores de rua. De volta à escola, os alunos devem comentar suas observações. O professor deve ficar atento aos aspectos observados pe- 
los alunos e questioná-los acerca dos motivos que existem para as diferenças constatadas. Relacionar com a história: Por que os porquinhos construíram as casas com materiais diferentes? Por que as pessoas constroem casas com materiais diferentes?

\section{EDUCAÇÃO E DIREITOS HUMANOS}

Acreditamos que essa atividade contemple as orientações metodológicas de:

REFERENCIAL TEÓRICO: a realidade social, econômica, política, cultural do meio, como referencial teórico;

DIREITOS FUNDAMENTAIS: a compreensão efetiva sobre a integralidade e a indivisibilidade dos direitos fundamentais, seu contexto histórico, seu caráter público e reclamável;

APRENDIZAGEM: ligada à vivência do valor da igualdade em dignidade e direitos para todos; propiciar o desenvolvimento de sentimentos e atitudes de cooperação e solidariedade;

Por outro lado, contribuem para que o aluno perceba as diferenças sociais e as condições que negam a dignidade do ser humano.

- Separar diferentes tipos de materiais (folhas, galhos, pedrinhas, garrafas pet, palitos de picolé, tampinhas pet, etc.) e pedir que em pequenos grupos montem casas;

Nessa atividade os alunos deverão trabalhar em grupos, deverão perceber que alguns materiais são mais fáceis de manipular, enquanto outros requerem maior planejamento. Na sequência, os alunos poderão testar suas construções e "soprar" as casas até caírem.

Após as atividades, os alunos devem ser convidados a comentar:

- o trabalho do grupo;

- a escolha do material;

- o planejamento necessário;

- a resistência da casa;

- a sensação de perder a casa etc.

Relacionar com a história: Seria a palha o material mais fácil de manusear para construir a casa do porquinho mais jovem? Seria a juventude, ou o fato de gostar de brincar, os fatores que o levaram a construir a casa de palha?

EDUCAÇÃO E DIREITOS HUMANOS 
Acreditamos que essa atividade contemple as orientações metodológicas de: INTERDISCIPLINARIDADE: não se pretende uma nova disciplina, mas uma formação abrangente;

PARTICIPAÇÃO NO TRABALHO DA ESCOLA: compreensão da íntima relação entre direitos humanos e formas de participação no trabalho da escola: colaboração, respeito, pluralismo, responsabilidade, prestação de contas;

COTIDIANO ESCOLAR: constatação da presença ou ausência, de defesa ou de violação de quaisquer direitos no cotidiano escolar;

REFERENCIAL TEÓRICO: a realidade social, econômica, política, cultural do meio, como referencial teórico;

DIREITOS FUNDAMENTAIS: a compreensão efetiva sobre a integralidade e a indivisibilidade dos direitos fundamentais, seu contexto históriCo, seu caráter público e reclamável;

APRENDIZAGEM: ligada à vivência do valor da igualdade em dignidade e direitos para todos; propiciar o desenvolvimento de sentimentos e atitudes de cooperação e solidariedade;

Por outro lado, acreditamos que a atividade possibilite o desenvolvimento da tolerância, da responsabilidade e da autonomia.

As próximas atividades serão apenas citadas, pois acreditamos que todas elas possam contribuir para o desenvolvimento da educação em Direitos Humanos, caracterizada na seção anterior, com a sensibilidade do professor, pois como afirma Calvino (1993, p. 221)

A poesia vive também pelo poder de irradiar hipóteses, divagações, associação de ideias em territórios distantes, ou melhor, de trazer a si e agregar ideias de várias proveniências, organizando-as numa rede móvel de referências e refrações, como através de um cristal.

Afinal, acreditamos que a humanização, nas palavras de Candido, aconteça não exclusivamente pelo diálogo leitor-texto-realidade, estimulado pela escola; mas, sobretudo, no espontâneo convívio leitor-livro.

Exemplo: CASA, MORADOR, TEMPESTADE

Quais são os "lobos" da nossa realidade.

Que tipos de violência aparecem na história? Só o lobo repre senta o perigo? O que os porquinhos fizeram para "Fazer justi ça com as próprias mãos"?

Sugira o tipo de construção mais adequado para a segurança de todos os porquinhos? Justifique sua ideia. 


\section{Considerações finais}

Para encerrar este artigo, nos abrigamos nas palavras de Mário Quintana (1973, p. 28): "A resposta certa, não importa nada: o essencial é que as perguntas estejam certas.." Assim, acreditamos que a literatura é uma experiência humanizadora por si só. As atividades sugeridas, na realidade, são pretextos, não importam nada, para que a contação de histórias, a pergunta certa, seja uma constante nas escolas. Eis a grande atividade na educação em Direitos Humanos: Contar histórias e compartilhar histórias. Histórias inventadas, histórias reais, histórias vividas ou ouvidas, histórias para viver, histórias para não morrer etc. O lúdico, o diálogo pela leitura e com a leitura, a imaginação devem ser a finalidade da contação de histórias.

Assim, acreditamos que a companhia do leitor até aqui, motivada pelo "pote de ouro no final do arco-íris" foi um percurso de grandes desafios e encantamentos. Se não conseguimos encerrar o assunto, dado que nunca foi nosso objetivo, proporcionamos uma experiência literária, cuja boniteza9, na expressão de Paulo Freire, não pode ser medida a não ser por aqueles cuja curiosidade leve aos livros e ao alargamento de horizontes.

\section{Referências}

BENEVIDES, Maria Victoria. Cidadania e Direitos Humanos. Cad. Pesq, São Paulo, n. 104, p. 35-75, 1998. Disponível em: http://www.fcc.org.br/pesquisa/ publicacoes/cp/arquivos/213.pdf. Acesso em: 11 jan. 2021.

BENEVIDES, Maria Victoria de Mesquita. Democracia e direitos humanos - reflexões para os jovens. In: ZENAIDE, M. de N. T. et al. (org.). Direitos Humanos: capacitação de educadores. João Pessoa: Editora Universitária/ UFPB, 2008. Disponível em: http://www.dhnet.org.br/dados/cursos/edh/ redh/04/4_7_maria_victoria_democracia_dh.pdf. Acesso em: 7 jan. 2021.

BENEVIDES, Maria Victoria. Educação em Direitos Humanos: de que se trata. Disponível em: http://www.hottopos.com/convenit6/victoria.htm. Acesso em: 11 jan. 2021.

CALVINO, Ítalo. Por que ler os clássicos. São Paulo: Companhia das Letras, 1993.

9 “[...] Boniteza, hace parte de la concepción de la vida, así como amorosidad, aprecio, solidaridad, utopía, alegría, esperanza, estética y genteidad. La vida debe ser bonita, no sólo la vida de un individuo, sino la realización de un pueblo." In: Diccionario Paulo Freire, 2015, p. 76. Disponível em: http://www.ts.ucr.ac.cr/binarios/libros/libros-000055. pdf. Acesso em: 11 jan. 2021 
CANDIDO, Antonio. O direito à literatura. In: CANDIDO, A. Vários escritos. 5. ed. Rio de Janeiro: Ouro sobre o azul, 2011. Disponível em: https:// edisciplinas.usp.br/pluginfile.php/3327587/mod_resource/content/1/ Candido\%200\%20Direito\%20à\%20Literatura.pdf. Acesso em: 11 jan. 2021.

CONTOS CLÁSSICOS. Os três porquinhos. Erechim: Edelbra, 2002. (n. 7)

FREIRE, Paulo. Professora sim, tia não: cartas a quem ousa ensinar. São Paulo: Olho d'água, 1993.

QUINTANA, Mário. Caderno H. Porto Alegre: Editora Globo, 1973.

SISTO, Celso. Textos \& pretextos sobre a arte de contar de histórias. 3. ed. Belo Horizonte: Aletria, 2012.

SOUZA, Celina. Políticas públicas: uma revisão de literatura. Sociologias, Porto Alegre, ano 8, n. 16, p. 20-45, jul. - dez. 2006.

STRECK, Danilo (coord.); REDIN, Euclides; ZITKOSKI, Jaime José. (org.) Diccionario Paulo Freire. Lima: CEAAL, 2015. Disponível em: http://www. ts.ucr.ac.cr/binarios/libros/libros-000055.pdf. Acesso em: 11 jan. 2021.

Recebido em: 14 de fevereiro de 2021. Aprovado em: 14 de maio de 2021. 
